\title{
ENTRE OS LIMITES DA PELE NEGRA: RESPOSTAS CORPORIZADAS AOS TEMORES DA ESSENCIALIZAÇÃO
}

Érica Giesbrecht ${ }^{1}$

Universidade de São Paulo, São Paulo, Brasil

Em minha pesquisa de doutoramento interessei-me pelo modo como grupos culturais afro-brasileiros reformularam as demandas dos movimentos sociais negros, através de práticas expressivas. O fato de os participantes desses grupos sambarem, dançarem jongos ou maracatus, no entanto, levanta questionamentos, tanto entre suas plateias, como entre seus estudiosos. Até que ponto essa prática incorreria no risco de se fortalecerem estereótipos que essencializam e reduzem os negros ao dominio da natureza, numa espécie de naturalização da cultura? Num panorama mais amplo, percebemos que as atuais politicas de apoio à diversidade, tanto nacionais quanto internacionais, também vêm sendo questionadas, pois estariam, de certo modo, levando à criação de modelos de comportamento, prescrevendo açóes, estéticas, muitas vezes instruindo como indivíduos que clamam pertencer a determinado grupo deveriam agir e ser. Neste artigo pretendo apontar caminhos para responder a estes questionamentos em dois niveis, usando a "pele negra" como limite entre açóes externalizadas e processos corpóreo-subjetivos. Para tratar do primeiro nivel, busco reflexóes êmicas sobre esses assuntos. Passando para um nivel mais profundo, tomo como ponto de partida o corpo, revelando não apenas suas capacidades de incorporação de valores socializados, mas também sua potencialidade como sujeito no mundo da cultura.

Palavras chave: comunidade negra, movimento negro, estereótipos, essencialização, corpo

1 A autora é pos-doutoranda no Departamento de Antropologia da Universidade de São Paulo. Contato: egiesbrecht@gmail.com 


\section{ESTEREÓtIPOS, ESSENCIALIZAÇÕES, RISCOS.}

Repiques de tambores complexamente polirrítmicos, geralmente cadenciados pelos de sonoridade mais grave. $\mathrm{O}$ colorido das saias, batas, lenços a rodopiar e se agitar pelo ar, numa poética visual vibrante e efusiva. Corpos se lançando no espaço em movimentos requebrados, dialogando com os tambores enquanto perfileram cortejos de maracatu, blocos de afoxé ou formam rodas de samba e jongo. Vozes, palmas e sorrisos convidando a plateia a fazer parte de uma grande celebração, um convite sedutor raramente declinado. É desse modo que se apresentam ao público grupos de cultura popular afro-brasileira sediados na cidade de Campinas, interior de São Paulo. Tais grupos escolheram formas expressivas tidas como tradições afro-brasileiras como suas performances artísticas, afirmando-se como portadores de tradições e memórias dos africanos e seus descendentes escravizados no Brasil e divulgando esse passado nas poéticas, sonoridades e movimentos que compõem tal legado musical.

No entanto a adoção desses modos de ser - jongueiros, sambadores, batuqueiros - não deixa de ser colocada em cheque. Logo após ter defendido minha tese de doutorado, fui entrevistada por uma colega, também antropóloga e com pesquisa direcionada a questões raciais, e questionada sobre a possível essencialização a que a prática desses repertórios estaria levando. Da mesma forma, conheci pessoas negras que não estavam envolvidas, mas acompanhavam os grupos culturais de longe, e se perguntavam se o engajamento em tais movimentos, em religiões de matriz afro, ou em outras práticas afins, era de fato necessário para se "ser" negro. Ainda entre espectadores das apresentações desses grupos culturais, cheguei a ouvir questionamentos similares. Seria essa a única possibilidade musical à qual esses negros teriam acesso?

Em primeiro lugar, tendo em vista "o lado de fora da pele negra", o objetivo desse artigo é refletir sobre essas questões a partir das experiências dos participantes dos grupos culturais negros da cidade de Campinas. Em seguida, partindo "da pele negra para dentro" pretendo mostrar como nesse universo de tambores, saias coloridas e rodadas, danças, palmas e cantoria, residem respostas corporificadas a essas questões, capazes de mobilizar e transformar poderosamente, para além dos discursos e práticas, posturas diante do mundo.

A formação dessas comunidades musicais remonta ao final dos anos 1980. Esses grupos se desenvolveram a partir de bases alicerçadas pelo movimento social negro em Campinas, cuja visibilidade era notável entre as décadas de 1960 e 1980. Durante esse período, consolidaram-se organizações negras tanto de ordem política - como o Movimento Negro Unificado, M.N.U. quanto cultural - como o Afoxé Ilê Ogum² e o Teatro Evolução ${ }^{3}$-, com profícuo diálogo entre si. A essas associações engajavam-se descendentes das antigas famílias negras, cujos ancestrais foram os primeiros libertos dos plantéis dos barões do café, e migrantes de diversas regiões do

2 Fundado em 1984, o Afoxé Ilê Ogum inspirava-se nos blocos de afoxé baianos. O grupo abriu os desfiles de carnaval de Campinas entre 1985 e 1989 e realizava apresentações de rua em outras épocas do ano.

$3 \mathrm{O}$ grupo de teatro Evolução reuniu pessoas com ou sem formação teatral, que desenvolviam tarefas múltiplas, desde a atuação e criação dos espetáculos, até sua produção e promoção. Dentre seus fundadores estavam Antônio Carlos Silva (TC, hoje diretor da Casa de cultura Tainã), o mestre Lumumba, Jonas Lemos e Jorge Mateus. As peças de seu repertório tinham sempre o tom da denúncia das condições de desigualdade, exclusão e preconceito sofridos pela população negra, constando dentre elas História do Samba, Sinfonia Negra, O Príncipe Poeta, Gangazumba, Encontro com Deus, dentre outras. Todas essas peças eram autorais e desenvolvidas a partir de um processo de criação coletiva. Em sua trajetória, que basicamente compreendeu a década de 1970, o grupo tinha como público muitas cidades do interior e do litoral do estado, investindo na criação de movimentos político-cultuais locais. 
país em busca de melhores condições de vida, que passavam a ocupar as periferias do município, economicamente atrativo a partir dos anos 1970.

Correntes ideológicas de educação popular, promovidas por centros comunitários de esquerda, atravessavam a agenda de ações dessas organizações sociais. Inspirados por práticas teatrais como as de Bertold Brecht e Augusto Boal, esses centros eram apoiados financeiramente por países socialistas e comunistas, oferecendo cursos de educação política abertos à população. Em função do fluxo de pessoas, essa orientação se infundiu ao movimento negro, unindo suas vertentes política e artística. Ainda que expressões como os jongos ou sambas de bumbo fossem conhecidas por alguns, não era exatamente a esse repertório que se recorria como emblema de um movimento artístico de resistência. A ênfase das escolhas recaía sobre as performances consideradas mais "politizadas" em comparação àquelas danças antigas, que já nem mesmo as famílias negras mais velhas mantinham. A única exceção era feita aos afoxés de rua, expressão que passava a ganhar notoriedade política na Bahia a partir dos anos 1970.

Tal orientação viria a mudar substancialmente na década de 1990, como resultado de uma conjunção de fatores. O desmantelamento de economias e organizações mundiais de esquerda e o consequente enfraquecimento da ênfase na arte explicitamente politizadora deixaram uma brecha para que outras linguagens redirecionassem o movimento negro da cidade. A abertura ideológica para novas possibilidades foi reforçada pela passagem de pessoas influentes como a folclorista Raquel Trindade, filha do poeta Solano Trindade, que veio a convite do Instituto de Artes da Universidade Estadual de Campinas para ministrar oficinas de danças afro-brasileiras e danças dos orixás a alunos de graduação em dança e em artes cênicas.

Disseminando repertórios expressivos até então pouco conhecidos em Campinas, e influenciado diretamente a criação dos grupos culturais da atualidade, Raquel Trindade renovava as possibilidades de emprego de culturas expressivas como ação de resistência. Para os participantes dos movimentos culturais negros que acreditavam nas performances como forma de expressão ideológica e política, tais danças traziam a memória dos negros de outras partes do Brasil, narradas em sons, cores e movimentos. Mas, por outro lado, essas danças eram capazes de incluir outras pessoas e suas questões. Para os que não estavam diretamente envolvidos com a militância dos movimentos negros, essa era uma oportunidade para "aprender mais sobre si mesmo", como ouvi várias vezes durante minha pesquisa de doutorado.

Numa breve descrição, podemos dizer que o grupo Urucungos surgiu em 1989, a partir das oficinas de Raquel Trindade. Até hoje ensaiam e apresentam o repertório ensinado durante o curso: basicamente esquetes de manifestações culturais propriamente ditas - como jongos, lundus, samba lenço, samba de roda, maracatu, coco, cirandas, dentre outras - estilizadas na década de 1940 por Solano Trindade, gerando pequenas coreografias cênicas desses legados afro-brasileiros. Com o passar dos anos incorporaram outra tradição musical, o samba de bumbo, tido como a expressão musical negra mais importante do interior estado de São Paulo, não apenas durante o período de escravidão, mas até as primeiras décadas do século XX. (Simson, 2009).

Já a Casa de Cultura Tainã foi o único centro cultural profícuo dentre vários criados pela prefeitura de Campinas na mesma época, e que foram extintos mais tarde por falta de subsídios. Apoiando-se principalmente nos ganhos adquiridos através de sua Orquestra de Tambores de Aço, a Casa Tainã sobreviveu e se tornou um centro comunitário de referência da cultura afro-brasileira em Campinas, dispondo hoje de uma arrojada estrutura disponibilizada à comuni- 
dade, que inclui biblioteca, laboratório de computadores, espaços para lazer e estúdio de som.

A partir dessas duas associações, surgiram muitas outras, geralmente desenvolvendo algum dos estilos musicais praticados pelas primeiras. Assim ocorreu com o "Jongo Dito Ribeiro", fundado em 2001. Alguns dos formadores desse grupo tiveram passagem pelo Urucungos e pela Casa Tainã, acumulando experiências e aprendizados. Hoje, a comunidade jongueira gere um centro cultural, a Fazenda Roseira, na qual, além de jongo, muitas outras atividades culturais acontecem, todas ligadas a legados culturais afro-brasileiros.

Mesmo carregando históricos de formação e repertórios diferentes entre si, esses grupos trazem algumas características em comum. São grupos musicais amadores e sem fins lucrativos, que reúnem pessoas interessadas na cultura popular negra. Fizeram, em primeiro lugar, uma escolha pelos repertórios musicais de matriz afro-brasileira, tidos como "tradicionais", e assim chamados por terem sido criados em algum capítulo da história dos africanos e de seus descendentes escravizados no Brasil ${ }^{4}$. E essa foi uma escolha emblemática, uma vez que esses repertórios reconstroem memórias sobre a vida daqueles ancestrais.

Uma pronta identificação com esse universo ancestralizado é mediada pelas expressões do corpo, que dança, canta e toca instrumentos percussivos. Esses repertórios reforçam uma ação política, criando espaços para reflexões sobre um modo de ser negro em Campinas nos dias de hoje. Para além do viés político, persistem, na compreensão de seus praticantes, dimensões ainda mais profundas da vida, incluindo visões espiritualizadas, prazerosas e afetivas sobre suas ações.

Dentre os inquietamentos levantados por essas práticas no meio acadêmico, questiona-se em que medida tais posturas incorreriam no risco de se promover um certo exotismo relacionado a grupos étnicos, ecoando-se a inquietação de estudiosos como Peter Fry (2005) sobre a questão da "racialização". Até que ponto não se estaria contribuindo para a criação de novos estereótipos raciais, alimentando antigos estigmas sociais, ou mesmo reforçando idiossincrasias como "negro tem samba no pé", "negros transam melhor", "negros jogam futebol bem"?

Observando a questão por outro prisma, notamos que as atuais políticas direcionadas aos bens culturais, tanto nacionais quanto globais, vêm se alinhando cada vez mais a políticas de apoio à diversidade, passando a ser igualmente questionadas 5 . Diante desse quadro, poderíamos nos perguntar, como fizeram Maio e Santos (2005), até que ponto essas formas de apoio à diversidade não estariam criando uma espécie de política de modelos de comportamento, prescrevendo ações, estéticas, ou criando "pedagogias raciais", instruindo como indivíduos, que clamam pertencer a determinado grupo, deveriam agir e ser.

4 Concordo com a proposição de Hobsbawm e Ranger a respeito das tradições (1984). A continuidade com o passado não é uma consequência natural, tornando as invenções essencialmente modernas. As "velhas tradições" não eram exatamente tradições no passado; eram apenas práticas. Iniciadas no passado, em algum momento que não podemos precisar, passam a ser ideologicamente nomeadas como tradições a partir de negociações do tempo presente.

5 No Brasil, a criação nacional de bens simbólicos se inicia com a exaltação à miscigenação no Estado Novo, cujas nuances se perpetuaram num ideal de integração nacional até o final do regime militar. Em seguida, nos primeiros anos da redemocratização do país, o reconhecimento das diferenças é preconizado, porém sob a orientação de uma lógica de mercado. Somente a partir do governo Lula, chega-se à visibilidade da diversidade e à inclusão de setores excluídos da cultura (Barbalho, 1998). 
Ao refletirem sobre a política de cotas raciais adotadas pela UNB, os autores observam o processo através do qual um comitê - que baseia sua legitimidade e imparcialidade sobre sua composição, que envolve estudantes, representantes de movimentos sociais negros e cientistas sociais - seleciona alunos com base na análise de fotografias e entrevistas. Isso os leva a concluir que se trata de um verdadeiro "tribunal racial", decidindo quem tem o direito de ser negro no vestibular de cotas da universidade.

Obviamente apoios à diversidade abrangem uma gama muito mais ampla de grupos sociais do que aqueles demarcados por ações afirmativas. O terreno dos fomentos culturais destinados à visibilidade negra, no entanto, é o lugar onde essas coisas se misturam. Nesse campo, tais apoios são disponibilizados lado a lado com apoios à diversidade sexual, comunidades tradicionais, grupos sociais marcados pela violência, dentre outros, porém produzem um debate muito mais acalorado, especialmente pela possibilidade de se estar reproduzindo a segregação ou se promovendo um racismo às avessas através da premiação de artistas que se declarem negros, ou de projetos diretamente ligados a temáticas negras.

Inserindo-se neste debate, o artigo apresenta reflexões divididas em duas sessões. Na primeira, questionamentos relativos às escolhas de repertório, sistemas de identificação e finalmente ao surgimento de fomentos culturais direcionados a artistas e produções negras são respondidos através de uma análise das ações desses grupos, basicamente orientada por noções elaboradas no campo da etnomusicologia. A segunda sessão, "da pele negra para dentro" aprofunda-se na questão dos usos do corpo, terreno de tantas disputas ideológicas no âmbito dos estudos raciais, nas práticas de dança e música dos participantes dos movimentos campineiros, buscando lições não verbalizadas que afluem de suas convivências musicais.

\section{AÇões NA SUPERFícIE: do LADO DE FORA DA PELE NEGRA}

Em obra lançada recentemente, Peter Fry (2005) demonstra como a noção de raça vem sendo socialmente reconstruída em diferentes contextos e como é capaz de direcionar ações e categorias de significado. A partir desta reflexão posiciona-se em relação às cotas e demais ações afirmativas de forma combativa: na contramão do mito da democracia racial, que Fry tem agora como uma utopia de reconhecimento da universalidade humana, essas políticas alimentadas em tempos de celebração da diversidade reforçariam as definições raciais e a consequente segregação. Seu posicionamento causou impacto no campo de estudos correlatos no Brasil e rendeu uma extensa bibliografia responsiva, filiando-se ou discordado de seus preceitos ${ }^{6}$. Fora do ambiente acadêmico, a preocupação com o reforço das diferenças raciais parece atingir mais pessoas. Ecoando o pensamento de Fry, em meio às plateias do movimento cultural afro-brasileiro de Campinas, tais questionamentos são provocados pelas próprias performances.

Dançar e tocar tambores cantando letras que remontam ao tempo da escravidão não seriam formas de se reforçar um modo de ser negro estereotipado? Para que esse investimento numa identidade negra? Não se estariam criando "distúrbios identitários" (AGIER 2001) na formação dos grupos da atualidade? Da mesma forma, ainda que se saiba que negros e brancos

6 Sobre cotas raciais ver Maio e Santos (2005), Maggie (2006); sobre fomentos culturais, Gruman (2012); sobre outras formas de ação afirmativa, ver Moehlecke (2009); sobre as políticas raciais de saúde, ver Maio e Monteiro (2005). 
compõem essas associações, questiona-se se a criação de grupos culturais autodeclarados "negros" não estaria reproduzindo a mesma segregação do passado. Há ainda uma terceira categoria de questões: num contexto em que a diversidade cultural parece estar em voga, e em que se fomentam ações culturais para a promoção de sua visibilidade, não se estariam criando novos "modos de ser negro" a partir de uma inédita política de valorização?

Iniciemos pela questão da retomada de repertórios musicais afro-brasileiros tidos como tradicionais. Em alguns momentos da história do Brasil a relação entre a cultura popular e a identidade nacional foi prescrita por uma intelectualidade movida por impulsos nacionalistas. $\mathrm{Na}$ década de 1930, nos conta Elizabeth Travassos (1997), as Missões Folclóricas coordenadas por Mário de Andrade se deparavam com uma dimensão mítica das expressões populares encontradas Brasil afora. Mas é preciso compreender o significado do "mítico" tanto para Andrade, quanto para os pensadores sociais contemporâneos a ele. Naquele contexto intelectual, a categoria mítica das manifestações expressivas brasileiras dialogava com uma acepção evolucionista largamente aceita. Enquanto tradições orais ou "danças dramáticas" seriam, ainda que de maneira primitiva, os meios pelos quais as camadas populares e iletradas da sociedade teriam de expressar seus anseios. (Cavalcanti 2006).

Já Hermano Vianna (2007) narra um episódio ocorrido em 1926 no qual intelectuais como Gilberto Freyre, Prudente de Morais Neto, Heitor Villa-Lobos e Luciano Gallet foram a convidados por Donga, Patrício Teixeira e Pixinguinha para "uma noitada de violão", na qual a discussão principal giraria em torno da criação de uma identidade nacional musical: "De um lado, representantes da intelectualidade e da arte erudita, todos provenientes de "boas famílias brancas". Do outro lado, músicos negros ou mestiços, saídos das camadas mais pobres do Rio de Janeiro". (Vianna 2007: 20).

Perceba o leitor que em ambos os momentos a iniciativa para se compreender, se apropriar e dar visibilidade às expressões populares partiu de uma elite intelectual dominante não necessariamente interessada na experimentação dessas vivências expressivas. $\mathrm{Na}$ recente formação dos grupos de cultura popular de Campinas, assim como em muitas partes do Brasil, existe uma sutil diferença: a iniciativa parte dos próprios interessados em performar essas expressões. $\mathrm{Na}$ perspectiva de James Scott (1990), estes seriam considerados os dominados do sistema. No entanto, confirmando o que Scott enuncia, suas performances produzem efeitos, reflexões, orientações e reposicionamentos diante do mundo. A apropriação desses conteúdos expressivos funciona justamente como mecanismo de reversão dos estigmas que forjam simbolicamente a dominação.

Lembro-me das palavras de Alceu Estevam, músico e diretor geral do grupo Urucungos, durante uma apresentação no 20 de novembro, dia da Consciência Negra, do ano de 2008. Durante os intervalos entre a apresentação de uma dança e outra, Alceu lembrava a plateia sobre a importância histórica daquele dia, uma conquista do Movimento Negro da década de 1970, escolhida por coincidir com a provável data da morte de Zumbi dos Palmares. Em seguida passou a falar sobre o "lugar do negro na sociedade". Dizia ele que o Urucungos não estava ali batucando e dançando por serem estas "coisas de negro", negando assim a associação com qualquer estereótipo.

$\mathrm{Na}$ visão de Alceu, não estavam ali fazendo o que se espera que negros façam, batucar e gingar, como que aceitando um papel raso projetado para eles. O grupo estava antes se apro- 
priando da visibilidade e dos espaços de reflexão possibilitados por um feriado que, "antes de mais nada, chama atenção para a consciência”. A fala de Alceu é apenas mais um exemplo, dentre tantos outros, de reflexão sobre o significado da prática de tais repertórios musicais. Longe do reforço de um estereótipo o que se quer é trazer a conhecimento público uma memória marginalizada tanto em seu conteúdo quanto em sua forma.

Há nas letras das canções, nos detalhes dos figurinos, na vivacidade do movimento dos corpos e no toque dos tambores, traços de memória que se contrapõem à literatura histórica relacionada ao período de escravidão no Brasil, cujos relatos geralmente se limitam a um passado degradante de submissões e rechaços sociais. Desde os repertórios praticados pelo Urucungos até aqueles explorados pelos grupos mais recentes, são acionadas teias de significados que remetem a momentos vitoriosos e episódios de manutenção da dignidade dos escravizados, mesmo sob um poderoso manto de repressão.

O heroísmo de ícones como Zumbi dos Palmares ou Ganga Zumba; a celebração da sagacidade das fugas, dos feitiços recaindo sobre os senhores; o agradecimento à proteção dos orixás, de São Benedito e de Nossa Senhora do Rosário e a lembrança das contribuições culturais trazidas pelos africanos para o Brasil perpassam as músicas e as danças desses grupos culturais. Há, portanto, uma outra perspectiva na narrativa da história dos africanos e seus descendentes no Brasil presente na prática desses repertórios. $\mathrm{O}$ que os praticantes querem é serem eles próprios os narradores de sua história, a partir de seus prismas e pontos de vista, algo que difere drasticamente de qualquer projeto intelectual já criado no Brasil.

É justamente através dessa retomada de noções de self, incorporação de memórias e, principalmente, por meio da reestruturação de suas posturas diante do mundo, ensaiadas a cada encontro, que a apropriação de outros bens culturais se torna possível. $\mathrm{O}$ envolvimento nessas práticas expressivas é capaz de subverter constrangimentos e estigmas sociais atravessados pelo racismo; empoderados, os participantes desses grupos culturais começam a repensar-se como agentes da cultura. Tornam-se produtores e sentem-se livres para também usufruir de outras produções culturais, adquirindo uma visão crítica a respeito de seus próprios consumos e usufruindo de acessos, antes negados pelo estigma. De fato, ir a um teatro, à livraria de um shopping, candidatar-se a uma universidade particular ou pública passaram a ser cada vez mais recorrentes entre essas pessoas.

Já a segunda categoria de questionamentos, recai sobre o fato de se unirem em grupos autodenominados "afro". A ação voluntária e ideológica em torno do investimento identitário de um grupo social incorreria no risco de se reproduzir a segregação ao invés de mina-la. Novamente sintetizando uma forma de se pensar sobre os referidos grupos culturais negros campineiros, Fry afirma: "O 'fracasso' do Movimento Negro na conquista de corações e mentes dos brasileiros decorre do conflito entre os princípios segregacionistas que estão no cerne da ideologia do Movimento e os anseios assimilacionistas que continuam fortes no senso comum brasileiro". (Fry 2005: 178)

Houve momentos em que participar de grupos sociais negros (de natureza religiosa, política, recreativa, esportiva, cultural, dentre outras) era um meio de se obter socialização e respaldo em uma comunidade acolhedora e protetora, frente à discriminação racial explicitamente ins- 
taurada na maior parte dos locais públicos da cidade de Campinas, e alhures em todo o Brasil ${ }^{7}$. Desde os tempos da escravidão eram comuns atividades coletivas como cultos, festas e reuniões entre os negros escravizados ao trabalho das fazendas de café (Nogueira 2001). Esse contexto ofereceu as bases para a formação de futuros agrupamentos urbanos em torno de festividades musicais, inicialmente sambas de bumbo e a partir dos anos 1940, bailes negros, blocos e as primeiras escolas carnavalescas (Giesbrecht 2011). Muitas dessas associações eram recriações de instâncias frequentadas por gente branca, nas quais negros não podiam tomar parte ${ }^{8}$.

Já os grupos de hoje concentram pessoas com diversificadas formações, condições econômicas e histórias de vida, ainda que sejam majoritariamente compostos por aquelas que se declaram negras e de baixa renda. Também são marcados por grandes diferenças etárias, reunindo avós, filhos, netos e bisnetos e aqui reside um elemento importante para a compreensão da formação dessas comunidades musicais em Campinas. Dentre os que hoje estão na faixa de seus 50 ou sessenta anos, muitos tiveram participação ativa em movimentos sociais negros como o Movimento Negro Unificado (M.N.U.), de caráter essencialmente político, em sua juventude. Já os mais velhos, hoje entre setenta e noventa anos, vivenciaram aqueles círculos de socialização marcados por música e dança do passado, como os bailes negros, sambas de bumbo e carnavais. Essas inter-relações comunitárias do passado foram vitais para que se formassem as associações do presente, já que tornavam muitas pessoas conhecidas e acessíveis entre si, de geração a geração.

Do mesmo modo que as associações do passado, as de hoje oferecem respaldos, acolhimentos e recriam redes de sociabilidade formando uma imensa teia de relações. Contudo, se anteriormente a experiência comunitária negra se desenvolveu a partir de um contexto de segregação explícita, a de hoje não parte diretamente da mesma necessidade, mas de uma ação voluntária. $\mathrm{O}$ novo tipo de participação demarca investimentos em modos de representação, visibilidade e ação política, além do sentimento de pertencimento a um grupo. Há uma carga profundamente ideológica atravessando este sentimento de pertença, tanto que não é preciso ser negro para se fazer parte dessas organizações, desde que se apoiem as mesmas causas.

Se as associações anteriores foram criadas num contexto em que o transito negro em esferas de sociabilidade brancas era impossível ou carregado por toda sorte de constrangimentos sociais, hoje os integrantes dessas associações desfrutam de relativa liberdade. Ainda que o racismo seja uma realidade em nosso cotidiano, atitudes deliberadas de preconceito passaram a fazer parte do "politicamente incorreto" e podem mesmo ser enquadradas como crime.

Some-se a isso um contexto atual em que a valorização da diversidade é celebrada globalmente e pelos mais diversos tipos de instâncias sociais. Nesse novo contexto, criticamente dife-

7 Exemplos de formação de comunidades negras se espalharam por todo o país, incluindo irmandades católicas devotas de Nossa Senhora do Rosário que pontilharam as regiões de exploração do ouro em Minas Gerais (Reily, 2010); áreas de produção agrícola do Nordeste Brasileiro (Souza, 2002) e até associações urbanas, como a "pequena África" que se criou em torno da famosa Tia Ciata, acolhendo especialmente aos negros que migravam do Nordeste e aportavam na cidade do Rio de Janeiro (Moura, 1983).

8 Em outro trabalho (Giesbrecht 2011), desconstruí a ideia de que a formação desses encontros para se dançar e festejar sinalizava a resignação às condições impostas à comunidade negra. Longe de serem espaços designados para negros, por algum mecanismo de controle superior, eram antes espaços criados por negros, nos quais se desenvolvia uma notória rede de sociabilidade, fortaleciam-se sentidos de pertença e se forjava uma comunidade musical negra. O erro não está em se reconhecer a segregação, mas em percebe-la como fonte de enfraquecimento moral da comunidade negra. 
rente dos anteriores, marcados por formas de repressão ofensiva, permanece a questão: se hoje as manifestações culturais negras não são proibidas ou rechaçadas como no passado, a que os agentes que atualmente nelas se envolvem estariam resistindo e de que forma? Para que investir nessas associações se hoje não são mais necessárias?

É justamente na livre escolha que permeia as novas experiências comunitárias que reside o incômodo. Seria o engajamento em associações nominalmente negras uma recriação da segregação? De fato essas associações não são "necessárias". Não é necessário se criar um clube de bailes negro pelo fato de negros não poderem frequentar bailes de brancos, por exemplo.

Contudo, se para dentro dos limites de cada grupo o emprego da performance produz sensibilidades nas quais se ancoram todas as relações humanas, e se intensificam os sentidos comunitários, para fora, em direção às plateias, outros tipos de sensibilização são acionadas. Alguns aspectos da musicalidade desses grupos remetem ao que Thomas Turino (2008) chamou de "música participativa": temas melódicos ou rítmicos repetitivos, repertórios que exijam muitas pessoas para serem executados, possibilidades de improvisação, dentre outros.

No pensamento de Turino, "participar" é estar envolvido com o processo musical, seja com instrumentos, canto, palmas, danças ou gestos, tornando-se parte componente do grupo performático. A música participativa é definida e estilisticamente modelada pelo objetivo essencial de valorizar até mesmo a mais simples forma de participação, e tem sucesso na medida em que consegue envolver o maior número de participantes, reais e potenciais (2008: 29-36). Ela difere de uma performance musical em que os músicos, como no concerto de uma orquestra, necessitam do silêncio da plateia para executarem uma obra musical, definindo-se claramente a quem cabe performar aquela música.

De fato, os elementos musicais citados eliminam distinções entre artistas e públicos, ajustando-os todos como participantes da performance musical em diferentes níveis e funções. Valendo-se da música como um poderoso instrumento de socialização e das relações que os músicos e bailarinos são capazes de criar com a plateia no momento da performance, o que esses grupos culturais fazem de fato é compartilhar seus valores envolvendo suas audiências em seu mundo expressivo, convidando-os a tomar parte dos coros do samba de bumbo, das rodas de jongo, dos cortejos de maracatu. Não raro, são essas experiências enquanto plateia participativa que levam muitas pessoas a se juntarem a esses grupos posteriormente, sendo acolhidos nos ensaios ou demais encontros internos como novos participantes. Através de som e movimento esses grupos demonstram sua permeabilidade para novos e diversificados engajamentos, respondendo a qualquer suspeita de recriação da segregação com calorosos acolhimentos musicais.

Finalmente, a questão envolvendo fomentos culturais destinados às expressões da diversidade tem sido discutida largamente pela opinião pública, pelo meio acadêmico e pelos próprios agentes desses grupos culturais. Por um lado, alguns se preocupam com a possibilidade de uma ditadura de comportamentos da qual as associações culturais estariam sendo vítimas, adequando-se ao que prescrevem os editais de apoio à suas manifestações culturais. Por esse viés, qualquer atribuição de valor à diversidade seria uma ação essencializante. Há ainda quem considere as políticas de valorização das diversidades assistencialistas. Como coloca Gruman (2012):

Vale a reflexão: até que ponto políticas de reparação reparam injustiças passadas? A partir de que ponto políticas de reparação transformam-se em assistencialistas? É possível uma política pública de cultura democrática baseada em critérios anacrônicos? O antigo "oprimido" pode ser o novo "opressor"? A negação do 
conceito de raça como referencial teórico na elaboração de políticas públicas é sinal de racismo do agente público? Qual o papel da meritocracia na elaboração de políticas públicas de cultura? Por que não estabelecer seriamente o anonimato como diretriz para avaliação dos projetos? Que há racismo no Brasil é inegável e provar a sua existência, em muitas situações é, se não impossível, improvável. Entretanto, tomar a sua existência como ponto de partida na discussão a respeito da elaboração de políticas públicas de cultura democráticas dificilmente ajudará na consolidação de uma democracia cultural no país.

Atravessados por essas correntes de opiniões e teorizações, e envolvidos na atual dinâmica de fomentos culturais, os participantes dos movimentos culturais negros refletem e se manifestam. Interessada em provocar suas respostas, lancei uma matéria publicada no jornal Folha de São Paulo na rede social Facebook, convidando-os nominalmente para um debate. $\mathrm{O}$ artigo mostrava um projeto para espetáculo de dança impedido de concorrer ao Prêmio de "Arte Negra" promovido pela Funarte em 2013. Em seu edital, o prêmio visava contemplar somente artistas negros e o impedimento de um diretor branco de participar do edital, ainda que sua companhia fosse composta por bailarinos negros, causou polêmica ${ }^{9}$. Recebi inúmeras respostas, mas dentre elas, quatro pareciam sintetizar as opiniões gerais:

O Edital é bem objetivo sobre essa questão. A FUNARTE e a SEPPIR criaram o prêmio para proporcionar aos produtores e artistas negros oportunidade de acesso a condições e meios de produção artística, conforme estabelecido pelo Plano Nacional de Cultura (Lei 12.343/2010) e pelo Estatuto da Igualdade Racial (Lei 12.288/2010). É como se fosse uma equiparação de igualdade aos acessos à linha de investimentos públicos ligados à produção artística. Normalmente, se formos comparar estatisticamente, a maioria dos contemplados são de artistas e produtores não negros. O centro do objeto é estimular esses artistas e produtores negros a se capacitarem (pois houve varias oficinas de formatação deste edital), para que no futuro a quantidade de propostas chegue também nas camadas que normalmente não têm condições e nem acesso e esses mecanismos. Por outro lado, Cooperativas Artísticas, como essa de Dança, por exemplo, que se especializaram na contemplação desses editais, observam essas oportunidades de mais um canal de linha de crédito, elaboram um projeto, com atores e bailarinos negros, fazem o espetáculo e ficam na expectativa de outros editais. Qual a contrapartida de fomento, a não ser apenas um direcionamento claro de mercado? Depois que termina o espetáculo, negros têm dificuldade de inserção neste mesmo mercado. Nada contra as Cooperativas, afinal, sobreviver de arte não é fácil para ninguém, mas o que se espera neste especifico edital é que os negros tenham controle total do seu produto, proporcionado um olhar e uma estética genuinamente afro-brasileira. Todos que estão participando do edital sabem dessas condições. Muitos vão chiar e talvez nem concordar com essas condições de exclusividade aos negros, mas não poderão dizer que não sabiam dessas regras, pois, se estão acostumados com as leituras e as regras de vários editais que participam - por que somente neste as regras não estão claras?” (Alceu Jose Estevam, diretor do grupo Urucungos Puítas e Quijêngues)

Bom, numa coisa o edital é claro e até na oficina de formação foi frisado: o preponente, seja pessoa física ou jurídica, tem que se autodeclarar negro. Embora eu não acredite que seja eficiente, a Funarte talvez esteja tendo mais controle quanto a exigir que os donos reais do projeto sejam negros, mesmo que numa Cia. de dança, por exemplo, o corpo do elenco seja misto, formados por brancos e negros. Sabe a história do "laranja"? Há risco de que aconteça isso, mas com essa companhia de dança se passa justamente o contrário. Mas no geral, esses editais são uma palhaçada. Mal formatados e muito fáceis de serem burlados. Fora que é muito pouco, quase nada propiciar aos negros esse tipo retratação versus todo um histórico e um conjunto de mazelas que passamos. E meio que jogar um osso no meio de um monte de cães famintos... É uma "reparação" que soa desrespeito. Mas enfim, "controversiando", pra que a mudança aconteça, tem que se começar de algum lado. (Viviane Silva, participante do grupo Urucungos Puítas e Quijêngues)

Eu acho que há varias formas de apoiar a cultura afro-brasileira, que está esquecida!!! Se o Edital da Furnarte usou a cor da pele para barrar projeto, está errado, é racismo, não podemos aceitar. Não devemos cometer os mesmos erros que a sociedade burguesa cometeu no passado. Zumbi dos Palmares dizia: Não podemos cometer os mesmos erros deles... Racismo tem que ser combatido, qualquer tipo ... (Bene de Moraes, Diretor

9 Fioratti, Gustavo. Funarte alega cor da pele e barra projeto de dança. Folha de São Paulo, São Paulo, 23 de março de 2013, Poder, acessado em 05/05/2015 em http://www1.folha.uol.com.br/fsp/poder/100047-funarte-alega-cor-da-pele-e-barra-projeto-de-danca.shtml. 
do Grupo Savurú)

Opa!! A questão é delicada, mas também não é tão difícil assim, né! Primeiro, tem a especificação do edital, "instituições privadas cujo representante legal, no ato da inscrição, se autodeclare negro", em relação a isso é bem simples: o representante não é preto!!! Logo não se enquadra no edital. Segundo, que a proposta do edital não é diminuir o que se abate no imposto de renda, mas possibilitar que os muitos gestores/produtores pretos mostrem a cara também, saca, poder gestar a grana, gastar a grana e etc. Depois vamos com calma em dizer quem comete racismo! Racismo é uma relação de PODER baseada na cor da pele, o edital vem pra tentar tratar de uma relação muito especifica que é a cor de quem produz (gesta a grana, gasta a grana e etc) e a proposta é mudar essa relação. Sabemos que nos editais culturais tem sempre os mesmos, uma coisa é o não negro falar sobre negros, outra coisa é o próprio negro falar sobre si, mas são pesos e medidas diferentes embora e talvez a intenção seja mesma! Uma coisa é fato! Quem tá afim de realmente mudar as estruturas do Brasil deixando-as mais coloridas, não pode ficar sentindo dor toda vez que se fala em algum tipo de ação afirmativa. (Ike Banto, participante dos grupo Urucungos e da Casa de cultura Tainã)

Expressos num fórum, ainda que corriqueiro e informal, os diálogos apresentam divergências e concordâncias próprias de um debate recorrente e dinâmico. Há quem considere tais políticas uma espécie de racismo às avessas e quem as considere uma forma de reversão do racismo. Há quem as considere políticas compensatórias, e há quem se ria do termo "compensação", uma vez que esses recursos ainda são poucos. Alguns enxergam o início do caminho em direção a condições igualitárias de acesso ao mercado cultural, mas jamais de maneira ingênua: não passam desapercebidos a seus olhos as inúmeras possibilidades de se burlarem tais critérios compensatórios, nem os perigos da criação de um novo nicho de editais, do qual artistas que já dominam a cena das premiações por incentivo fiscal continuem usufruindo após aprenderem como se adequar a seus termos e condições.

Na dinâmica das relações e práticas de participantes do Urucungos, do Jongo Dito Ribeiro, da Casa de Cultura Tainã e de tantos grupos semelhantes, encontramos argumentos poderosos que transcendem os limites de uma explicação rasa de reforço de estereótipos. Percebemos a força das formas expressivas, escolhidas como meio para apropriarem-se de sentidos de self e história de vida; observamos o modo pelo qual a mobilização sensível e estética é capaz de provocar transformações nas posturas de cada indivíduo diante do mundo e nos deparamos com reflexões êmicas refinadamente elaboradas sobre questões que, até mesmo no meio acadêmico, causam reticências, embaraços e receios sobre que posturas assumir, como a questão de fomentos culturais. Tais respostas, materializadas no mundo das ações, extraem sua força de um nível experiência ainda mais profundo, sobre o qual passaremos a refletir agora.

\section{A dimensão profunda: da pele negra para dentro}

Enquanto pesquisadores, antropólogos ou etnomusicólogos, estamos sempre interessados nas motivações de nossos interlocutores para executarem suas ações. Buscamos compreendê-las e, muitas vezes, para explicarmos estes "porquês", nos valemos de outras necessidades, como "identidade", "ação política", "ação afirmativa”, dentre outras. Raramente compreendemos as ações de nossos interlocutores sem tais fins. É claro que eles existem, mas em se tratando de envolvimentos estéticos, sensibilidades e expressões como dança e música conectando pessoas, existem outros domínios também.

Como já mencionei anteriormente, a música praticada pelos grupos afro de Campinas está muito próxima da definição de Thomas Turino sobre "música participativa" (2008). Ao invés de 
um aprendizado musical sistemático em que a música vai sendo ensinada passo a passo, muitas vezes levando-se muito tempo para se chegar a um resultado final capaz de produzir sentido estético, os novatos são diretamente inseridos na música e na dança propriamente ditas, executada pelos membros mais experientes. Envolvem-se primeiramente em funções mais simples, que não comprometem o resultado final e, com o passar do tempo, podem assumir funções musicais mais complexas. Deste modo, não é preciso aprender um conteúdo para apenas posteriormente se experimentar a música. Não é preciso adquirir uma técnica antes de se conhecer e se deixar envolver pelo resultado musical. Como o produto, a performance musical, já está sempre garantida por músicos mais experientes, o processo acaba ganhando maior importância. Nesse sentido, esse fazer musical permite uma liberação maior, uma vez que seus participantes podem se entregar relaxadamente aos processos e experiências envolvidos em sua prática. Assim é possível acessar níveis profundos da experiência sensível que é o envolvimento numa comunidade cuja mais intensa atividade de integração se realiza musicalmente. Como ilustra a fala de André Luís Moraes, membro da Comunidade Dito Ribeiro, sobre suas sensações numa roda de jongo:

No jongo muita coisa me contagia, o espaço da roda é de uma energia impar desde o inicio, o tocar do tambor me remete a uma ancestralidade, que mesmo distante, eu sinto muito perto; sendo assim, tremer, se emocionar são coisas simples de serem sentidas. Inexplicavelmente o tambor, os pontos e as rodas me contagiam...O jongo me faz entender a minha ancestralidade e todo caminho que me trouxe até ali. Nunca vi o jongo como algo novo, apesar de ter conhecido há uns 5 anos, mas pra mim ele é algo que me acompanha há muito tempo. Algo ancestral.

Os engajamentos corpóreos, sensíveis e emocionais propiciados por essa prática musical, especialmente caracterizada pela interdependência que promove entre seus participantes, pode ser um elemento chave aqui. Relembrando, este não deve ser considerado o único elemento entrelaçando pessoas no âmbito dessas comunidades. Existem objetivos óbvios como o desejo de visibilidade e as intenções políticas dessas ações. Há, porém, uma clara escolha de como atingir tais objetivos. E é exatamente no modo escolhido por estas comunidades que reside a força de suas inter-relações. Os participantes do Jongo Dito Ribeiro, do Urucungos, da Casa de Cultura Tainã e de tantos outros grupos de cultura negra de Campinas fizeram da música e da dança um espaço para entregas sensíveis e emocionais do corpo e da mente, ainda que essa experiência tenha consequências no campo político/ideológico.

As dimensões acessadas por essa prática musical estão intimamente ligadas a um universo sensório, no qual o corpo perfaz o terreno das inscrições sensíveis e ao mesmo tempo, através de suas capacidades, é fonte de agências que vão muito além da racionalidade ou da intelectualidade. No universo das culturas expressivas afro-brasileiras, o corpo negro, investido de habilidades dançantes e musicais específicas, torna-se o objeto de discussões e controvérsias.

Sempre que falamos em "corpo", tememos incorrer no risco da essencialização. Isso muitas vezes silencia os debates, levando ao que Judith Becker (2004: 08) chamou de "conhecimento desincorporado", uma forma de negar o corpo na tradição intelectual ocidental, forjada pelo Iluminismo, mas que remonta aos escritos de santo Agostinho. Apesar dos esforços das correntes iluministas para desvencilhar o pensamento religioso de outras formas de conhecimento, a abominação do corpo ainda os unia: se para a igreja o corpo era o lócus do pecado opondo-se à elevação do espírito, para o pensamento científico devia submeter-se à mente, única salvação da condição bestial. O lema cartesiano "Cogito ergo sum" tornou-se a premissa do pensamento ocidental, remetendo o corpo ao status de prisão da mente e do espírito. 
Entretanto, a sensação de "autenticidade" que as performances de legados afro-brasileiros parecem nos dar quando executadas por corpos negros abre caminhos para pensarmos nas operacionalizações de sentido que levam a uma noção do autêntico, construída nas relações empáticas entre nossos corpos. Ideias como a de que "o negro tem samba no pé" podem nos revelar muito mais do que a disseminação de um mero senso comum; podem nos mostrar a importância que o corpo ganha em esquemas perceptivos e imaginários. Concordando com Csordas (1990), o corpo é a unidade a partir da qual nos pensamos em relação aos outros, sendo sua imersão prática nas interações cotidianas essencial para as narrativas pessoais. $\mathrm{O}$ corpo está embutido em nossos pensamentos, e simultaneamente orienta nossa imaginação a respeito do mundo.

Para além de medidor de nossas relações e interpretações de mundo, o corpo é também um lugar de infinitas possibilidades de produção e reelaboração de conhecimentos e memórias, como nos mostra o estudo de Yvonne Daniel (2005) sobre a dança de seguidores de religiões afro-americanas. Levando em conta que as estratégias de dominação dos povos africanos trazidos para as Américas incluíram muitas vezes a aniquilação e a proibição de seus festejos, ou destruição de seus aparatos rituais - como instrumentos musicais, objetos sagrados e vestimentas cerimoniais - Daniel nos chama a atenção para a maneira misteriosa e subversiva pela qual todo esse legado de conhecimentos foi memorizado pelos corpos, como estratégia de preservação e transmissão por muitas gerações.

Essas danças eram momentos de reconstrução de cosmologias, conhecimentos e estados emocionais anteriores à escravidão, aos quais se queria acessar e incorporar, reiterar, portanto. Ao mesmo tempo funcionavam como forma de promover resistência e liberação do corpo e da mente num contexto cativo, neste sentido promovendo a liberação de um subjugo estruturado no esqueleto e nos músculos e permitindo a inscrição de novas verdades sobre eles. A incorporação de orixás dançantes possibilitava a liberação das estruturas incorporadas nas práticas de castigo e trabalho exaustivo cotidianas, substituindo-as por outras, perfazendo assim uma resistência corporizada à dominação ${ }^{10}$.

Daniel nos mostra como, na dança ritual Ioruba, múltiplos canais comunicacionais são despertados, engatilhando inúmeras significações não verbais. A dança sagrada alcança desdobramentos sociais e cosmológicos para além do ritual; articula esteticamente sistemas de crença, econômicos, históricos e sociais e também desempenha o papel de uma "medicina social" (2005: 53). A autora descreve a incorporação da matemática na performance dos tambores; a incorporação de conhecimentos botânicos na utilização de ervas e raízes para banhos de cura; a incorporação de conhecimentos filosóficos na dança dos adoradores e a incorporação dos ensinamentos sobre o poder divino e a integridade moral da comunidade nos rituais coletivos.

E estes usos do corpo eram refinadamente estratégicos. Consentidas pelo senhorio colonial, essas danças desempenhavam uma dupla funcionalidade no sentido da manutenção da vida num contexto de total subserviência. Por um lado, deslumbravam aos donos das fazendas e casas

10 Em tempo, contrariando uma visão funcionalista ou mecanicista sobre a relação entre a incorporação de orixás e a liberação do corpo, tomo por base a perspectiva construtivista disseminada por Tia DeNora (2000), segundo a qual, até mesmo o uso de música industrializada propicia (ou produz affordances) para a construção do corpo nos ambientes em que está inserido. Assim, as reações corpóreas aos ambientes sonoros são compreendidas por um viés que abandona a ideia de música como texto estruturado e corpo como continente estático de órgãos, mas se prende à ideia de que utilizamos sons para manter estados corporais. 
grandes por seu exotismo, pelo ritmo ou pelo movimento dos quadris, tendo sido muitas vezes incorporados nas festividades dos senhores brancos como uma espécie de tempero exótico. Entretanto, dançar também era um meio de se manter o culto aos ancestrais e as libertações do corpo e da mente, permitindo a inscrição de memórias de nações africanas inteiras nos músculos dos dançarinos.

Entre os grupos culturais de Campinas, os usos do corpo são analogamente eficazes produzindo a incorporação de memórias, conhecimentos e provocando sensações de plenitude. Podemos perceber o envolvimento nessas performances como uma retomada da valorização do corpo e de uma herança negra, ambos socialmente estigmatizados ao longo da história. Memórias, para além dos planos externos evidenciados nas performances, são reapropriadas pela própria reestruturação dos corpos desses dançarinos e músicos, transformando suas posturas diante das condições sociais impostas por uma cidade como Campinas.

Há uma estratégia sutil em se dançar memórias, lançando-se mão de uma linguagem não discursiva ou verbalizada, mas diretamente ligada ao mundo sensível. Se ao invés de temer o risco da essencialização nos ativéssemos à potência desse mecanismo para se incorporar costumes, hábitos, valores e verdades, perceberíamos que o corpo é um receptáculo e também um meio poderoso para se produzir narrativas de um grupo social. Basta compreendermos que os usos do corpo não essencializam ninguém; somos nós, quando não conseguimos nos desvencilhar de nossas heranças cristãs/cartesianas, que essencializamos o corpo e compreendemos qualquer ação relacionada a ele como algo de ordem menos elevada.

Partindo dos corpos e da agência dos participantes dos grupos afro-brasileiros, dança e música são empregadas como meio de apropriação da história negra no Brasil, apresentando-nos um caminho corpóreo para o conhecimento e a percepção do mundo há muito tempo esquecido.

Acredito que os participantes dessas comunidades musicais negras invistam no corpo sensório, despertado pela música e pela dança, as dimensões mais importantes de suas vidas. Empregam-no como uma forma altamente eficaz de apropriação da própria história e, ao incorporá-la, se valem de todas as capacidades do corpo para retransmiti-la. Quem sabe não seria essa a sua grande lição, para nós, que olhamos de fora? Remeter ao corpo as questões mais caras, explorar suas capacidades de interação, mobilização e posicionamentos diante do mundo é justamente desessencializa-lo, mostrar que ele não é da ordem das coisas "naturais", "bestiais", "pecaminosas", mas um poderoso instrumento para se pensar e viver a cultura.

\section{RefERÊnCIAS Bibliográficas}

Agier, Michel. 2001. "Distúrbios identitários em tempos de globalização". Mana, 7(2). Consultado em 12 de outubro de 2014 http://www.scielo.br/pdf/mana/v7n2/a01v07n2. pdf)

Becker, Judith. 2004. Deep Listeners: Music, Emotion and Trancing. Bloomington: Indiana University Press.

Barbalho, Alexandre. 1998. Relaçôes entre Estado e cultura no Brasil. Ijuí: Unijuí. 
Carvalho, José Jorge. 2004. Pp. 65-83. “Metamorfoses das tradições performáticas afro-brasileiras: de patrimônio cultural a indústria do entretenimento". In Celebrações e saberes da cultura popular: pesquisa, inventário, crítica, perspectivas. Editado pela FUNARTE-IPHAN. Brasília: CNFCP.

Cavalcanti, Maria Laura de Castro. 2006. "Tema e variante do mito: sobre a morte e ressurreição do Boi”. Mana 12 (1). Consultado em 25 de agosto de 2014 (http://www.scielo.br/pdf/ mana/v12n1/a03v12n1.pdf)

Costa, António Firmino da Costa. 2001. "Identidades Culturais Urbanas Em Época De Globalização”. Revista Brasileira De Ciências Sociais 17(48): 15 - 30.

Csordas, Thomas. "Embodiment As A Paradigm For Anthropology”. Ethos, Urbana, v. 18, n. 1, p. 5-47, 1990.

Daniel, Yvonne. 2005. Dancing Wisdom: Embodied Knowledge in Haitian Vodou, Cuban Yoruba, and Babian Candomblé. Urbana: University of Illinois Press.

DeNora, Tia. Music in Everyday Life. Cambridge: Cambridge University Press, 2000.

Fioratti, Gustavo. 2013. "Funarte alega cor da pele e barra projeto de dança". Folha de São Paulo, São Paulo, 23 de março de 2013, Poder. Consultado em 05 de maio de 2015 (http://www1. folha.uol.com.br/fsp/poder/100047-funarte-alega-cor-da-pele-e-barra-projeto-de-danca.shtml).

Fry, Peter. 2005. A persistência da raça: ensaios antropológicos sobre o Brasil e a África austral. Rio de Janeiro: Civilização Brasileira.

Giesbrecht, Érica. 2001. A Memória em Negro - Sambas de Bumbo, Bailes Negros e Carnavais construindo a comunidade negra de Campinas. Campinas: Pontes Editores.

Grumman, Marcelo.2014 “Tentativas de racialização das políticas culturais”. Cultura e Mercado. Consultado em 06 de maio de 2014 (http://www.culturaemercado.com.br/pontos-de-vista/tentativas-de-racializacao-das-politicas-culturais/)

Hobsbawm, Eric e Terence Ranger. 1997. A invenção das Tradições. Rio de Janeiro: Paz e Terra. Maio, Marcos Chor \& Santos, Ricardo Ventura. 2005. "Política de Cotas Raciais, 'os Olhos da Sociedade' e os Usos da Antropologia: o Caso do Vestibular da Universidade de Brasília (UnB)”. Horizontes Antropológicos, 11(23): 181-212.

Maggie, Yvonne. 2006. “Uma Nova Pedagogia Racial?” Revista USP, 68 (22): 112-129.

Maggie, Yvonne e Cláudia Barcellos Rezende (orgs.). 2002. Raça como retórica: a construção da diferença. Rio de Janeiro, Civilização Brasileira.

Moehlecke, Sabrina. 2009 “As políticas de diversidade na educação no governo Lula”. Cadernos de Pesquisa, 39(137): 461-487.

Moura, Roberto. 1993. Tia Ciata e a pequena África no Rio de Janeiro. Rio de Janeiro, Funarte.

Nogueira, Lenita. W. M. 2001. Música em Campinas nos últimos anos do Império. Campinas: Editora da Unicamp.

Pereira, M. E., Álvaro, J. L., Oliveira, A. C., Dantas, G. S. 2011. "Estereótipos e essencialização de brancos e negros: um estudo comparativo". Psicologia E Sociedade, 23(1): 144-153

Reily, Suzel. 2010. "Musicalidade, Colonialismo e Comunidades de Prática nas Minas Gerais do Século XVIII". Tese apresentada em concurso para docente titular, UFMG (não publicado).

Ribeiro, Hugo L. 2007."Folclore versus Párafolclore”. Música E̊ Cultura 2 (1): 01-08.

Rodrigues,Carmen I. 2006. "Caboclos na Amazônia: a identidade na diferença”. Novos Cadernos NAEA 9(1): 119-130.

Scott, James. 1990. Domination and the Arts of Resistance: Hidden Transcripts. New Haven: Yale University Press. 
Simson, Olga Rodrigues. 2009. Núcleo de Samba Cupinzeiro: o samba paulista e suas histórias. Campinas: Editora Arte Escrita, CD 1.

Souza, Marina M. 2002. Reis negros no Brasil escravista - bistória da festa de coroação de rei congo. Belo Horizonte: Editora da UFMG.

Travassos, Elizabeth. 1997. Os mandarins milagrosos: arte e etnografia em Mário de Andrade e Béla Bartók. Rio de Janeiro: Funarte - Zahar.

Turino, Thomas. 2008. Music as Social Life: The Politics of Participation. Chicago: University of Chicago Press.

Vianna, Hermano. 2007. O mistério do samba. Rio de Janeiro: Jorge Zahar/UFRJ.

\section{BETWEEN THE BOUNDARIES OF BLACK SKIN: A CORPOREAL RESPONSE TO THE FEARS OF ESSENTIALIZATION}

In my doctoral research, I discussed how African-Brazilian cultural groups reshape the demands of black social movements through their expressive practices. The fact that the participants of these groups dance samba, jongos or maracatus is, however, object of controversy. It is questioned whether, within this practice, stereotypes become reinforced, essentializing and reducing black people to the realm of nature, in a sort of naturalization of culture. In a broader perspective, I defend that the Brazilian laws of cultural promotion which support "cultural diversity" have become questioned for possibly creating political role models, prescribing actions, aesthetics, or "racial pedagogies", as well as instructing individuals who claim to belong to a particular group how to act and be. In this article, I intend to point out ways to respond to these issues on two levels, using the "black skin" as a boundary between outsourced actions and bodily subjective processes. Regarding the first level, I seek an emic reflection on the subject matter; then, taking the body as a starting point, the article aims to reveal not only the body's ability to incorporate socialized values, but also its potential as a subject in the world of culture, transforming, subverting and affirming shared truths within current black musical communities .

Keywords: black community, stereotypes, essentialism, body

Recebido em: 2014-01-31

Aceitado em: 2015-07-10 